• 研究报告・

\title{
丹霞梧桐群体遗传结构及其遗传分化
}

\author{
武星粀 ${ }^{1}$ 陈 璐 ${ }^{1}$ 王敏求 ${ }^{1}$ 张 原 $^{1}$ 林雪莹 ${ }^{1}$ \\ 李秀玉 ${ }^{1}$ 周 宏 $^{2}$ 文亚峰 $^{1^{*}}$ \\ 1 (中南林业科技大学风景园林学院, 长沙 410004) \\ 2 (广东省韶关市野生动植物保护办公室, 广东韶关 512000)
}

摘要：丹霞梧桐(Firmiana danxiaensis)是分布于我国韶关地区北部丹霞地貌的特有物种, 其分布范围狭窄, 种群数 量小。本文利用EST-SSR分子标记位点, 分析丹霞梧桐群体(丹霞山组群和南雄组群)的遗传多样性和遗传结构, 研 究群体的分化历史, 探讨该物种的可能分布和科学保护策略。结果表明: 丹霞梧桐总的遗传多样性中等 $(H t=$ 0.631), 群体内遗传多样性较高 $(H s=0.546)$, 遗传变异主要存在于群体内 $(79.66 \%)$, 但不同地理组群间存在显著的 遗传分化 $\left(F_{\mathrm{ST}}=0.150\right)$ 。长期地理隔离和现代人为干扰是形成丹霞梧桐当前遗传变异模式的主要原因。 STRUCTURE分析可将研究群体划分为清晰的两个基因库(gene pool), 其遗传结构与系统发育地理格局之间有密 切关系。丹霞梧桐不同地理群体经历了独立的进化路线, 但丹霞山群体的杂合性高, 遗传背景更为复杂。近似贝 叶斯运算法(Approximate Bayesian Computation, $\mathrm{ABC}$ )分析表明, 丹霞山和南雄地理群体在10万年前由同一个祖先 群体分化而来, 分化时有效群体大小分别为7,290和5,550。结合丹霞梧桐的遗传变异和生态位信息, 可推测丹霞梧 桐曾广泛分布于南岭地区, 受第四纪第三次亚冰期的影响, 南岭北部的丹霞梧桐群体因气候剧烈变化而灭绝, 仅 在南岭南部适宜的环境中得以保存并繁衍至今, 丹霞山和南雄是丹霞梧桐最主要的两个冰期避难所。在全面掌握 丹霞梧桐的自然分布, 开展就地保护的基础上, 通过建立种质资源戋、人工种苗扩繁、自然回归试验等措施, 对于 该物种的异地保护、种群恢复和开发利用具有重要意义。

关键词：群体遗传结构; 遗传分化; 遗传多样性; 近似贝叶斯算法; 微卫星标记; 丹霞梧桐

\section{Population structure and genetic divergence in Firmiana danxiaensis}

Xingtong Wu ${ }^{1}$, Lu Chen ${ }^{1}$, Minqiu Wang ${ }^{1}$, Yuan Zhang ${ }^{1}$, Xueying Lin ${ }^{1}$, Xinyu $\mathrm{Li}^{1}$, Hong Zhou ${ }^{2}$, Yafeng Wen ${ }^{1 *}$

1 Central South University of Forestry and Technology, Changsha 410004

2 Wildlife Conservation Office of Shaoguan, Guangdong, Shaoguan, Guangdong 512000

\begin{abstract}
Firmiana danxiaensis is an endemic plant species which is narrowly distributed in the northern parts of Shaoguan, Guangdong, China. To devise appropriate conservation strategies for this rare species, we examined the population structure and estimated the demographic history of nine natural populations using 18 EST-SSR markers. The results revealed a moderate degree of total genetic diversity $(H t=0.631)$ at the species level but high genetic diversity within populations $(H s=0.546)$. Strong genetic differentiation existed between two groups of Danxiashan and Nanxiong $\left(F_{\mathrm{ST}}=0.150\right)$. This current pattern might have arisen from prolonged geographical isolation and human disturbances. STRUCTURE analysis demonstrated that whole population can be divided into two distinct gene pools, closely related by their geographic location and having experienced independent evolutionary routes. The genetic background of Danxiashan was more complicated than that of Nanxiong. Approximate Bayesian Computation (ABC) analysis indicated that divergence time between the two groups could be 100,000 years BP, and their effective population size were 7,290 and 5,550 individuals, respectively. Combining the information of genetic variation with niche modelling, we inferred that F. danxiaensis might have been widely distributed around the Nanling Mountain in the Quaternary period. Populations located in the northern of Nanling Mountain likely became extinct due to climate change.
\end{abstract}

收稿日期: 2018-08-13; 接受日期: 2018-11-28

基金项目: 国家林业局野生植物保护项目和韶关市野生动植物保护办公室项目(2016ZWZY06)

* 通讯作者 Author for correspondence. E-mail: wenyafeng7107@163.com 
Danxiashan and Nanxiong provided the main refuges for the species during the last ice age. Being a rare species with small population sizes, better ecological investigation of natural populations and in situ conservation and implementation of restoration strategy are important measures to conserve this species.

Key words: population genetic structure; genetic divergence; genetic diversity; Approximate Bayesian Computation; EST-SSR marker; Firmiana danxiaensis

植物的现代分布和遗传结构受多种生物和非 生物因素的影响, 其中气候和地质变化是最主要的 非生物因素，会直接导致种内和种间的遗传分化 (Hewitt, 1996, 2004)。中国亚热带地区地形复杂, 气 候环境多样, 是全球生物多样性热点地区之一 (Myers et al, 2000; 应俊生, 2001)。2010年, “中国丹 霞” 成功申报并被列入世界自然遗产, 丹霞地貌作 为一个地貌类型被世界所承认(彭华, 2011)。“中国 丹霞”地处亚洲东部湿润地区, 其特有的地质地貌 和地理环境, 为多种子遗植物的保存提供了良好的 条件, 是我国亚热带地区生物多样性原地保护最重 要的自然生境(彭少麟, 2011)。该地区的植物资源与 分布、生态演替、遗传变异和多样性保护研究广受 关注。

梧桐科是一个多型科, 形态特征极为多样化 (解新明等, 2003)。该科植物的现代地理分布主要是 在热带和亚热带地区, 但在地质历史上, 非洲、欧 洲、亚洲和北美洲都有分布, 是第三纪子遗植物(徐 颂军和徐祥浩, 2001; 徐颂军, 2002)。梧桐科植物起 源古老, 形态多样, 特有性强, 是研究热带、亚热带 植物遗传变异分布格局及其历史成因, 了解古气候 和地质变化的理想材料。中国梧桐属(Firmiana)植 物共有4种, 全部为中国特有(徐颂军, 2002), 分别 是梧桐(F. platanifolia)、云南梧桐(F. major)、海南梧 桐(F. hainanensis)和丹霞梧桐(F. danxiaensis), 这4 个种的地理分布除梧桐的栽培分布区较广外, 其他 均属窄域分布类型。其中最具特色的是1987年在广 东丹霞山自然保护区发现的丹霞梧桐(徐祥浩等, 1987), 是丹霞山最主要的特征种, 也是丹霞地貌的 特有物种, 目前仅在韶关地区的丹霞山和南雄市境 内有分布。

丹霞梧桐, 小乔木, 花期4-5月, 花呈紫红色, 雌雄异花同株, 风媒传粉为主。果实夢䒿果, 种子 圆球形。其根系发达, 抗逆性强, 耐干旱和贫瘦, 适 于庭院栽植和用作先锋造林树种。丹霞梧桐树形优 美, 花色美丽, 秋色叶金黄, 亦是很好的园林观赏
树种。丹霞梧桐被发现以来, 由于其自然分布区狭 窄, 种群数量小, 已被列入《中国物种红色目录》(汪 松和解炎, 2004) “极危”等级, 是国家二级重点保护 野生植物。目前, 丹霞梧桐相关研究工作较少, 主 要集中于资源调查(陈璐等, 2018)、地理区系(罗晓 䒯等, 2015)、分布地地貌特征(欧阳杰和黄进, 2011) 和群体遗传分析(Chen et al, 2014)等。2015年, 南雄 市苍石寨也发现了丹霞梧桐, 使该种的自然分布从 丹霞山向北推进了 100 多公里。丹霞梧桐在南雄市 境内的发现提示我们, 我国亚热带其他典型丹霞地 貌区可能也有该物种的分布, 但目前, 关于丹霞梧 桐的全域分布、谱系地理学和种群保护研究开展较 少，不利于该珍稀物种的有效保护。

植物核基因组和叶绿体基因组具有不同的进 化方式、进化速度和基因突变率，选择适合的基因 组分子标记方法有利于阐明遗传变异的分布格局 和时空变化规律。传统的植物谱系地理学研究多通 过叶绿体基因组序列的变异, 分析特定物种的群体 遗传结构、进化和生态历程。叶绿体基因组单亲遗 传, 进化速度慢, 基因突变率低(Demesure et al, 1995), 分子标记结果通常反映了更为远古的历史 进化事件。而核基因组呈双亲遗传, 微卫星标记 (SSR)突变率高、变异丰富、遗传信息量大(Jarne \& Lagoda, 1996; Selkoe \& Toonen, 2006), 更利于检测 和揭示物种的近期进化及历史事件, 如瓶颈效应、 群体扩张、隔离和迁移等。中国亚热带地区地形和 气候的异质性高, 在整个第四纪冰期并未被大面积 的山地冰川覆盖, 但该地区仍经历了复杂的气候变 化, 并且保留了很多第三纪子遗植物的残遗群体 (陶君容, 1992; 应俊生, 2001)。第四纪冰期和间冰 期对植物的现代分布、遗传结构、种内分化等产生 了深刻的影响(Harrison et al, 2001; Qiu et al, 2011)。 相对于地球漫长的地质史, 探索第四纪冰期相对较 短的地质年代对物种进化和现代分布的影响, 核基 因组微卫星标记是适合的研究方法。

基于此, 本文以我国亚热带丹霞地貌的特有种 
丹霞梧桐为研究材料, 利用EST-SSR分子标记位点, 分析丹霞梧桐群体的遗传多样性和遗传结构; 研究 群体的进化和遗传分化历史; 探讨该物种的可能分 布区域和对环境的适应性。研究工作有利于该极小 种群植物的保护和回归自然, 同时, 对于揭示中国 亚热带丹霞地貌的植物系统进化, 了解丹霞地貌的 古气候和地质变化等也具有重要意义。

\section{材料和方法}

\section{1 材料}

2016年9月至2017年5月，在野外全面调查的基 础上, 从丹霞梧桐的现有分布地采集 9 个群体共213 个单株样本用于实验分析, 每群体样本数量15-30 株不等。采集新鲜、健康的嫩叶, 硅胶干燥保存, 用 于DNA提取。根据它们的分布地 9 个群体可分为丹 霞山(DXS)和南雄(NX)两个大的地理组群, 其中丹 霞山组群包括锦湖(JH)、老苗圃(LMP)、韶石山(SS)、 阳元山(YYS)和长老峰(ZLF) 5 个群体, 南雄组群包 括鹗蓄湖(QWT)、水库 1 (SK1)、水库 2 (SK2) 和柴岭 (WT) 4 个群体 (表 1)。选择 18 个多态性丰富的 EST-SSR 位点用于实验分析 (MH053446-053461; KF048045; KF048051)(表2)。

\section{2 方法}

\subsection{1 基因分型}

利用改良CTAB法提取样本DNA (Tsumura et al, 1995), 2\%的琼脂糖凝胶电泳检测DNA的浓度和质 量, 符合质量要求的 DNA 统一稀释为 $10 \mathrm{ng} / \mu \mathrm{L}$, $-20^{\circ} \mathrm{C}$ 保存待用。18对多态性引物, 合成苂光引物, 苂光接头分别为FAM, HEX, TAMRA。PCR扩增体 系20 $\mu \mathrm{L}$, 其中含 $2 \times$ Taq PCR Master Mix (Tiangen)
$10 \mu \mathrm{L}, \mathrm{F}$ 和R端引物各 $1 \mu \mathrm{L}, \mathrm{DNA}$ 模板 $3 \mu \mathrm{L}, \mathrm{ddH}_{2} \mathrm{O}$ $5 \mu \mathrm{L}$ 。采用Touch-down PCR扩增程序: $94^{\circ} \mathrm{C}$ 预变性 $4 \mathrm{~min}, 94^{\circ} \mathrm{C}$ 变性 $40 \mathrm{~s}, 65^{\circ} \mathrm{C}$ 退火 $35 \mathrm{~s}$ (每个循环减 $1^{\circ} \mathrm{C}$ ), $72^{\circ} \mathrm{C}$ 延伸30 s, 共 10 个循环; $94^{\circ} \mathrm{C}$ 变性 $40 \mathrm{~s}, 55^{\circ} \mathrm{C}$ 退 火35 s, $72^{\circ} \mathrm{C}$ 延伸 $30 \mathrm{~s}$, 共30个循环; $72^{\circ} \mathrm{C}$ 延伸 $10 \mathrm{~min}$, $4{ }^{\circ} \mathrm{C}$ 保存。ABI3730测序仪对SSR扩增产物进行基因 分型, Gene Marker 2.0软件收集基因分型结果。

\subsection{2 遗传参数分析}

利用GenALEx 6.3软件(Peakall \& Smouse, 2006) 统计各群体的等位基因数 $(\mathrm{Na})$ 、期望杂合度 $(\mathrm{He})$ 、 观测杂合度 $(H o)$ 和近交系数 $\left(F_{\mathrm{IS}}\right)$ 等, MS-tools 计算 各位点的多态性信息含量 $(P I C)$ 。采用Hp-Rare 1.0 软件(Kalinowski, 2005)计算等位基因和私有等位基 因丰富度(Ar和pAr)。FSTAT 2.9.3 (Goudet, 1995)用 于估算总遗传多样性 $(H t)$ 、群体内遗传多样性 $(H s)$ 和遗传分化系数 $\left(F_{\mathrm{ST}}\right.$ 和 $\left.G_{\mathrm{ST}}\right)$ 。采用Arlequin 3.5软件 (Excoffier \& Lischer, 2010)对组群间、群体间和群体 内的遗传变异进行AMOVA方差分析。

GenALEx 6.3软件对群体间地理距离(取自然 对数)和遗传距离 $\left[F_{\mathrm{ST}} /\left(1-F_{\mathrm{ST}}\right)\right]$ 矩阵的相关性进行 Mantel检验。采用Bottleneck软件(Cornuet \& Luikart, 1996)检测群体是否经历瓶颈事件, 选择逐步突变 模型(stepwise mutation model, SMM)和双相突变模 型(two-phased mutation model, TPM)的Wilcoxon单 侧检验法。

\subsection{3 遗传结构分析}

利用Poptree 2.0软件(Takezaki et al, 2010)的邻 接法(neighbor-joining, $\mathrm{NJ}$ )构建基于 $D_{A}$ 遗传距离的 聚类分析图。STRUCTURE 2.3.3 (Pritchard et al, 2000) 用于群体遗传结构分析，K值设定为2-9, 每个值运

表1 丹霞梧桐 9 个群体的地理位置及样本数量

Table 1 Locality information and sample size of the nine Firmiana danxiaensis populations

\begin{tabular}{|c|c|c|c|c|c|}
\hline 组群 Group & 群体 Population & 编号 Codes & 纬度 Latitude $(\mathrm{N})$ & 经度 Longitude (E) & 数量 Number \\
\hline \multirow{5}{*}{$\begin{array}{l}\text { 丹霞山 } \\
\text { Danxiashan } \\
\text { (DXS) }\end{array}$} & 锦湖 Jinhu & $\mathrm{JH}$ & $25^{\circ} 2^{\prime} 20.24^{\prime \prime}$ & $113^{\circ} 44^{\prime} 52.80^{\prime \prime}$ & 23 \\
\hline & 老苗圃 Laomiaopu & LMP & $25^{\circ} 2^{\prime} 22.24^{\prime \prime}$ & $113^{\circ} 44^{\prime} 59.51^{\prime \prime}$ & 21 \\
\hline & 韶石山 Shaoshishan & SS & $24^{\circ} 56^{\prime} 43.33^{\prime \prime}$ & $113^{\circ} 45^{\prime} 17.60^{\prime \prime}$ & 15 \\
\hline & 阳元山 Yangyuanshan & YYS & $25^{\circ} 2^{\prime} 46.08^{\prime \prime}$ & $113^{\circ} 44^{\prime} 7.32^{\prime \prime}$ & 30 \\
\hline & 长老峰 Zhanglaofeng & ZLF & $25^{\circ} 1^{\prime} 34.70^{\prime \prime}$ & $113^{\circ} 44^{\prime} 19.87^{\prime \prime}$ & 29 \\
\hline \multirow{4}{*}{$\begin{array}{l}\text { 南雄 } \\
\text { Nanxiong } \\
\text { (NX) }\end{array}$} & 鹗䒧湖 Yuanyanghu & QWT & $25^{\circ} 6^{\prime} 58.53^{\prime \prime}$ & $114^{\circ} 11^{\prime} 30.70^{\prime \prime}$ & 27 \\
\hline & 水库1 Shuiku1 & SK1 & $25^{\circ} 6^{\prime} 58.63^{\prime \prime}$ & $114^{\circ} 12^{\prime} 25.62^{\prime \prime}$ & 23 \\
\hline & 水库2 Shuiku2 & SK2 & $25^{\circ} 7^{\prime} 12.58^{\prime \prime}$ & $114^{\circ} 12^{\prime} 30.57^{\prime \prime}$ & 21 \\
\hline & 柴岭 Chailing & WT & $25^{\circ} 7^{\prime} 17.53^{\prime \prime}$ & $114^{\circ} 12^{\prime} 16.21^{\prime \prime}$ & 24 \\
\hline
\end{tabular}


表2 18个位点在丹霞梧桐样本中的遗传多样性参数

Table 2 Genetic diversity of 18 loci for Firmiana danxiaensis

\begin{tabular}{|c|c|c|c|c|c|c|c|}
\hline $\begin{array}{l}\text { 位点 } \\
\text { Locus }\end{array}$ & $\begin{array}{l}\text { 等位基 } \\
\text { 因数 } \\
\text { Number } \\
\text { of allele } \\
(\mathrm{Na})\end{array}$ & $\begin{array}{l}\text { 总遗传多样性 } \\
\text { Total } \\
\text { genetic } \\
\text { diversity for } \\
\text { the species }(H t)\end{array}$ & $\begin{array}{l}\text { 群体内遗传多样性 } \\
\text { Genetic } \\
\text { diversity } \\
\text { within } \\
\text { populations }(H s)\end{array}$ & $\begin{array}{l}\text { 遗传分化系数 } \\
\text { Interpersonal } \\
\text { inbreeding } \\
\text { coefficient } \\
\left(F_{\mathrm{ST}}\right)\end{array}$ & $\begin{array}{l}\text { 标准遗传分 } \\
\text { 化系数 } \\
\text { Gene } \\
\text { differentiation } \\
\text { factor }\left(G_{\mathrm{ST}}\right)\end{array}$ & $\begin{array}{l}\text { 多态性信息含量 } \\
\text { Polymorphism } \\
\text { information } \\
\text { content (PIC) }\end{array}$ & $\begin{array}{l}\text { 登录号 } \\
\text { Accession } \\
\text { number }\end{array}$ \\
\hline unigene_21904 & 9 & 0.651 & 0.590 & 0.102 & 0.094 & 0.577 & MH053446 \\
\hline unigene_9882 & 9 & 0.670 & 0.546 & 0.217 & 0.185 & 0.608 & MH053447 \\
\hline unigene_33644 & 7 & 0.726 & 0.618 & 0.171 & 0.148 & 0.680 & MH053448 \\
\hline unigene_15157 & 8 & 0.800 & 0.722 & 0.094 & 0.098 & 0.765 & МH053449 \\
\hline unigene_23055 & 9 & 0.562 & 0.500 & 0.136 & 0.111 & 0.486 & MH053450 \\
\hline unigene_60653 & 5 & 0.692 & 0.598 & 0.153 & 0.137 & 0.639 & MH053451 \\
\hline unigene_30066 & 6 & 0.588 & 0.554 & 0.064 & 0.057 & 0.498 & MH053452 \\
\hline unigene_37667 & 3 & 0.402 & 0.320 & 0.223 & 0.205 & 0.331 & MH053453 \\
\hline unigene_25213 & 4 & 0.578 & 0.510 & 0.135 & 0.118 & 0.515 & MH053454 \\
\hline unigene_36790 & 13 & 0.745 & 0.582 & 0.240 & 0.219 & 0.717 & MH053455 \\
\hline unigene_5197 & 9 & 0.638 & 0.514 & 0.219 & 0.194 & 0.611 & MH053456 \\
\hline unigene_48018 & 5 & 0.525 & 0.506 & 0.038 & 0.035 & 0.419 & MH053457 \\
\hline unigene_31908 & 15 & 0.700 & 0.640 & 0.080 & 0.085 & 0.659 & MH053458 \\
\hline unigene_25861 & 4 & 0.526 & 0.523 & 0.007 & 0.006 & 0.418 & MH053459 \\
\hline unigene_42278 & 7 & 0.745 & 0.632 & 0.165 & 0.152 & 0.704 & MH053460 \\
\hline unigene_35652 & 10 & 0.733 & 0.597 & 0.205 & 0.186 & 0.711 & MH053461 \\
\hline Fir_SSR25d-F & 5 & 0.549 & 0.478 & 0.126 & 0.130 & 0.475 & KF048045 \\
\hline Fir_SSR81d-F & 3 & 0.527 & 0.398 & 0.285 & 0.244 & 0.422 & KF048051 \\
\hline 均值 Mean & 7.278 & 0.631 & 0.546 & 0.150 & 0.135 & 0.569 & \\
\hline
\end{tabular}

算10次, Burn in Period和MCMC (Markov Chain Monte Carlo)的迭代参数分别为 100,000 和 50,000 。利 用STRUCTURE HARVESTER软件(Earl \& vonHoldt, 2012)和 $\Delta K$ 数值的分布, 确定最优基因库数 ( $K$ 值)。

利用CLUMPP 1.1.2 (Jakobsson \& Rosenberg, 2007) 计算基于最优 $K$ 值的个体隶属系数( $\mathrm{Q}$ 值), DISTRUCT 1.1 (Rosenberg, 2010)将群体遗传结构以图形方式可 视化输出。基于遗传距离矩阵, 利用GenALEx 6.3 软件对所有个体样本的遗传关系进行主成分分析 (PCoA)。

\subsection{4 群体分化历史分析}

利用DIY ABC软件(Cornuet et al, 2014)的近似 贝叶斯算法(Approximate Bayesian Computation)对 丹霞梧桐群体的历史事件进行推测, 主要包括群体 的分化时间、有效群体数量的变化以及群体混合事 件(admixture)的比率等。根据STRUCTURE 2.3.3得 出的最优 $K$ 值(基因库)、系统发育树结果及相关地质
资料，检测以下 4 种历史进化事件，依据后验概率 数值(posterior probability, PP) 确定最优进化事件。

进化事件1: 丹霞山和南雄群体由一个共同的 祖先群体分化而来 $(t 1)$ 。

进化事件2: 未知群体和南雄群体先由一个共 同的祖先群体分化而来( $t 1)$, 未知群体经历瓶颈事 件 $(t a)$, 形成现在的丹霞山群体。

进化事件 3: 南雄群体先从未知群体中分化而 来 $(t 1)$, 未知群体经历了瓶颈事件 $(t b)$, 形成现在的 丹霞山群体。

进化事件 4: 未知群体经历了瓶颈事件形成现 在的丹霞山群体 $(t 1)$, 南雄群体从丹霞山群体中分 化而来 $(t b)$ 。

DIY ABC软件基于近似贝叶斯算法，根据溯祖 理论，运用自然群体的复杂进化事件模型，在95\% 的置信水平下，基于Logistic回归，使用最接近模拟 数据 $1 \%$ 的观测数据来估测每个进化事件的后验概 
率, 后验概率值最大者, 为最优进化事件(每个进化 事件进行 $1,000,000$ 次模拟, 共 $4,000,000$ 次的数据模 拟)。相关参数设置见附录 1 , 其他相关设置依据DIY $\mathrm{ABC}$ 软件的用户指南。

\section{结果}

\section{1 遗传多样性}

18 个EST-SSR 位点共检测到 131 个等位基因 $(\mathrm{Na})$, 不同位点的等位基因数从3个(unigene_37667 位点)到 15 个(unigene_31908位点)不等, 平均为 7.278 (表2)。在种的水平, 丹霞梧桐总的遗传多样性 $(H t)$ 为 0.631 , 群体内遗传多样性 $(H s)$ 为 0.546 。从群 体水平进行分析 (表 3), 其平均等位基因数在 3.167-4.444之间，平均期望杂合度 $(\mathrm{He})$ 为 0.536 。以 群体内最小样本数 15 为基数, 长老峰(ZLF)群体具 有最高的等位基因丰富度 $(A r)$ 和私有等位基因丰富 度 $(p A r)$, 其值分别为 3.850 和 0.380 。各群体在多个位 点显著偏离Hardy-Weinberg平衡, 表现为杂合子数

表3 丹霞梧桐 9 个群体的遗传多样性参数
-0.056 , 平均值为 -0.229 。

对于丹霞山(DXS)和南雄 $(\mathrm{NX})$ 两个组群而言 (表4), 其期望杂合度 $(\mathrm{He})$ 分别为 0.552 和 0.517 , 群 体内遗传多样性 $(H s)$ 分别为 0.564 和 0.527 。以组群内 最小样本数 95 为基数, 丹霞山群体的等位基因丰富 度 $(A r)$ 和私有等位基因丰富度 $(p A r)$ 分别为5.371和 1.602, 南雄群体分别为4.836和1.065。

\section{2 群体遗传分化}

AMOVA分析结果表明, 丹霞山和南雄两组群 间的遗传变异占总变异的 $15.06 \%(P<0.01)$, 群体 间占5.28\% $(P<0.01)$, 群体内个体间的遗传变异最 高, 占总变异的79.66\% $(P<0.01)($ 表5), 说明丹霞 梧桐的遗传变异主要存在于群体内的个体之间, 其 次, 组群间(丹霞山和南雄)存在较大的遗传变异, 同一组群内群体间的遗传变异则相对较小。

丹霞梧桐群体间的遗传分化系数 $\left(F_{\mathrm{ST}}\right.$ 和 $\left.G_{\mathrm{ST}}\right)$ 分 别为 0.150 和 0.135 (表2), 在种的水平表现出较高的 遗传分化。不同地理组群内的遗传分化很小, 其中 丹霞山群体的遗传分化系数为 0.075 , 南雄群体为

Table 3 Genetic diversity parameters of the nine Firmiana danxiaensis populations

\begin{tabular}{|c|c|c|c|c|c|c|c|}
\hline $\begin{array}{l}\text { 群体 } \\
\text { Population }\end{array}$ & $\begin{array}{l}\text { 编号 } \\
\text { Codes }\end{array}$ & $\begin{array}{l}\text { 等位基因数 } \\
\text { Number of } \\
\text { allele }(\mathrm{Na})\end{array}$ & $\begin{array}{l}\text { 期望杂合度 } \\
\text { Expected } \\
\text { heterozygosity }(\mathrm{He})\end{array}$ & $\begin{array}{l}\text { 观测杂合度 } \\
\text { Observed } \\
\text { heterozygosity }(\mathrm{Ho})\end{array}$ & $\begin{array}{l}\text { 等位基因 } \\
\text { 丰富度 } \\
\text { Allelic } \\
\text { richness (Ar) }\end{array}$ & $\begin{array}{l}\text { 私有等位基因 } \\
\text { 丰富度 } \\
\text { Private allelic } \\
\text { richness }(p A r)\end{array}$ & $\begin{array}{l}\text { 近交系数 } \\
\text { Inbreeding } \\
\text { coefficient }\left(F_{\mathrm{IS}}\right)\end{array}$ \\
\hline 锦湖 Jinhu & $\mathrm{JH}$ & 3.778 & 0.539 & 0.719 & 3.520 & 0.320 & $-0.345^{* * *}$ \\
\hline 老苗戒 Laomiaopu & LMP & 3.778 & 0.543 & 0.638 & 3.540 & 0.190 & $-0.189 * * *$ \\
\hline 韶石山 Shaoshishan & SS & 3.389 & 0.544 & 0.765 & 3.370 & 0.150 & $-0.409 * * *$ \\
\hline 阳元山 Yangyuanshan & YYS & 4.444 & 0.548 & 0.673 & 3.820 & 0.220 & $-0.203^{* * *}$ \\
\hline 长老峰 Zhanglaofeng & ZLF & 4.389 & 0.584 & 0.665 & 3.850 & 0.380 & $-0.178^{* * *}$ \\
\hline 鸳㟢湖 Yuanyanghu & QWT & 4.056 & 0.533 & 0.648 & 3.580 & 0.230 & $-0.198^{* * *}$ \\
\hline 水库1 Shuiku1 & SK1 & 3.167 & 0.447 & 0.495 & 2.990 & 0.140 & $-0.056 * * *$ \\
\hline 水库2 Shuiku2 & SK2 & 3.778 & 0.544 & 0.712 & 3.470 & 0.130 & $-0.310 * * *$ \\
\hline 柴岭 Chailing & WT & 4.222 & 0.545 & 0.623 & 3.770 & 0.150 & $-0.175^{* * *}$ \\
\hline 平均值 Mean & & 3.889 & 0.536 & 0.660 & 3.546 & 0.212 & -0.229 \\
\hline
\end{tabular}

*** $P<0.001$, 表示该群体极显著偏离哈代-温伯格平衡.

*** $P<0.001$, representing the population significantly deviate from Hardy-Weinberg Equilibrium.

表4 丹霞梧桐两组群间的遗传多样性参数

Table 4 Genetic diversity parameters of the two Firmiana danxiaensis groups

\begin{tabular}{|c|c|c|c|c|c|c|}
\hline $\begin{array}{l}\text { 组群 } \\
\text { Group }\end{array}$ & $\begin{array}{l}\text { 期望杂合度 } \\
\text { Expected } \\
\text { heterozygosity } \\
(\mathrm{He})\end{array}$ & $\begin{array}{l}\text { 群体内遗传多样性 } \\
\text { Genetic diversity } \\
\text { within populations (Hs) }\end{array}$ & $\begin{array}{l}\text { 等位基因丰富度 } \\
\text { Allelic richness } \\
(A r)\end{array}$ & $\begin{array}{l}\text { 私有等位基因 } \\
\text { 丰富度 } \\
\text { Private allelic } \\
\text { richness ( } p A r)\end{array}$ & $\begin{array}{l}\text { 标准遗传分化系数 } \\
\text { Gene differentiation } \\
\text { factor }\left(G_{\mathrm{ST}}\right)\end{array}$ & $\begin{array}{l}\text { 基因流 } \\
\text { Gene flow } \\
(\mathrm{Nm})\end{array}$ \\
\hline 丹霞山 Danxiashan (DXS) & 0.552 & 0.564 & 5.371 & 1.602 & 0.075 & 6.941 \\
\hline 南雄 Nanxiong (NX) & 0.517 & 0.527 & 4.836 & 1.065 & 0.053 & 9.326 \\
\hline
\end{tabular}


表5丹霞梧桐群体间分子方差分析 $(A M O V A)(P<0.01)$

Table 5 Results of analysis of molecular variance (AMOVA) from populations of Firmiana danxiaensis $(P<0.01)$

\begin{tabular}{lllll}
\hline 变异来源 & $\begin{array}{l}\text { 自由度 } \\
\text { Source of variation }\end{array}$ & $\begin{array}{l}\text { 方差和 } \\
\text { Sum of squares }\end{array}$ & $\begin{array}{l}\text { 变异组分 } \\
\text { Variance components }\end{array}$ & $\begin{array}{l}\text { 占总变异比例 } \\
\text { Percentage of variation (\%) }\end{array}$ \\
\hline 组群间 Among groups & 1 & 171.218 & 0.7352 & 15.06 \\
群体间 Among populations & 7 & 111.824 & 0.2576 & 5.28 \\
群体内 Within populations & 417 & $1,621.42$ & 3.8883 & 79.66 \\
总计 Total & 425 & $1,904.462$ & 4.8811 & - \\
\hline
\end{tabular}

0.053, 说明在各组群内基因交换较为频繁, 基因流 大小分别为6.941和9.326 (表4)。

\section{3 群体遗传结构}

STRUCTURE分析结果显示: 当 $K=2$ 时出现明 显拐点且取得最大值, $\Delta K$ 数值的分布在3-6之间趋 于平缓, 说明 9 个群体最有可能被分为 2 个基因库 (gene pool), A和B (图1)。根据单株个体分配到不同 基因库的比例, 来源于丹霞山的 5 个群体全部分配 到了基因库 $\mathrm{A}$, 基因库 $\mathrm{B}$ 则包含了来源于南雄的 4 个 群体, DISTRUCT输出结果直观显示了各群体的成 分组成(图2)。随着 $K$ 值的增大 $(K=3 、 K=4)$, 丹霞 山组群中出现了新的基因库, 长老峰(ZLF)、韶石 山 (SS)群体逐渐从丹霞山同源基因库中分离出来, 显 示出与其他群体的较大差异, 而南雄的 4 个群体中 没有出现新的基因库。

邻接法(NJ)构建的各群体系统发育树上, 9 个群 体分为 2 个分支, 分别对应丹霞山组群和南雄组群 (图3)。不同单株个体的主成分分析结果(PCoA)(图4) 和STRUCTURE及NJ结果一致。群体间 $F_{\mathrm{ST}} /\left(1-F_{\mathrm{ST}}\right)$ 和地理距离(对数变换) $(\ln K m)$ 矩阵的Mantel检验结 果表明, 丹霞梧桐群体的遗传距离和地理距离之间 极显著相关, 相关系数为 $R=0.833(P=0.01)$ (图5)。

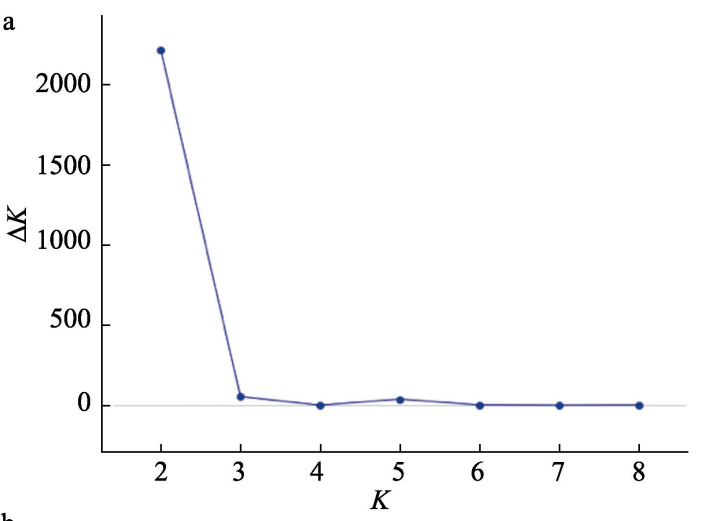

b

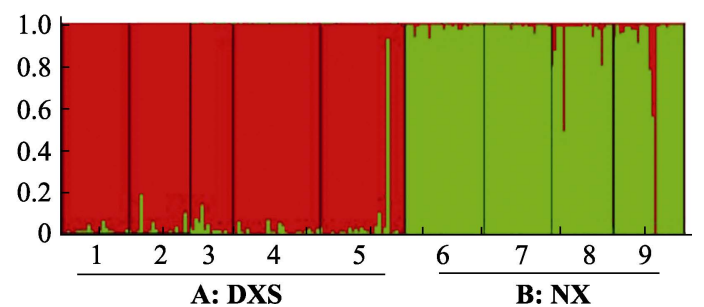

图1 基于EST-SSR标记的丹霞梧桐群体遗传分析。(a)基于 Evanno等(2005)所得的相应的 $\Delta K$; (b) STRUCTURE分析的 直方图 $(K=2$ 时, $\Delta K$ 值最大)。每个坚条代表1个群体。DXS 代表丹霞山组群; NX代表南雄组群。

Fig. 1 Genetic structure for Firmiana danxiaensis based on EST-SSR markers. (a) The corresponding $\Delta K$ statistics calculated according to Evanno et al (2005). (b) Histogram of the structure analysis for the model with $K=2$ (showing the highest $\Delta K$ ). Each vertical bar represents one population. DXS represent Danxiashan group; NX represent Nanxiong group.

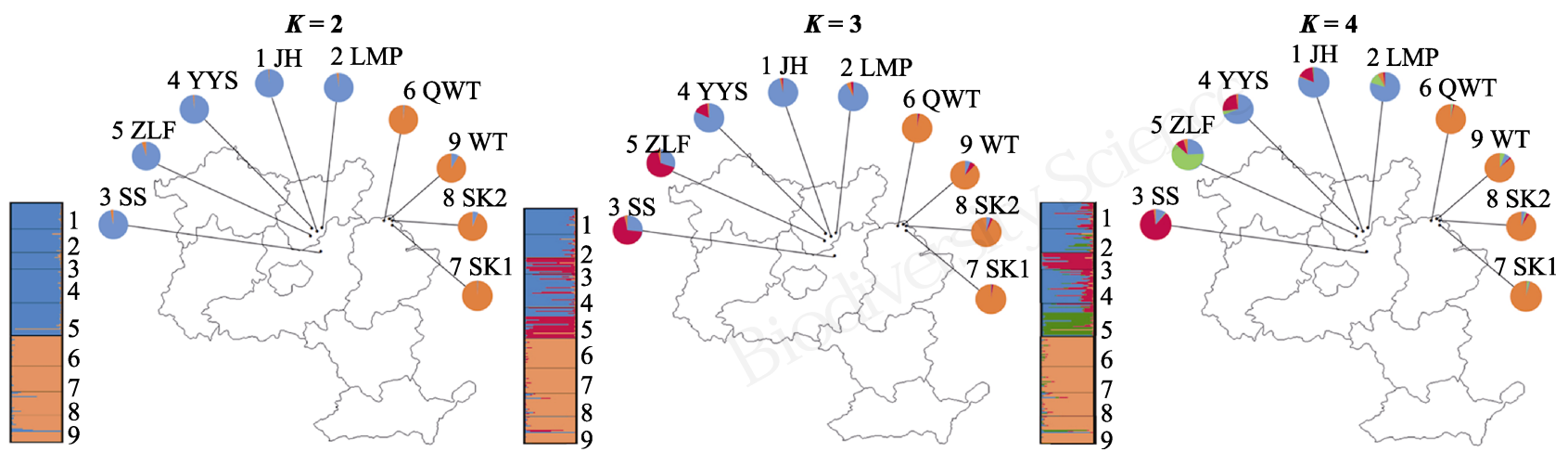

图2 基于CLUMPP和DISTRUCT分析的丹霞梧桐群体遗传结构 $(K=2,3,4)$ 。缩写含义同表 1 。

Fig. 2 Genetic structure for Firmiana danxiaensis based on CLUMPP and DISTRUCT $(K=2,3,4)$. Meanings of abbreviations are shown in Table 1. 


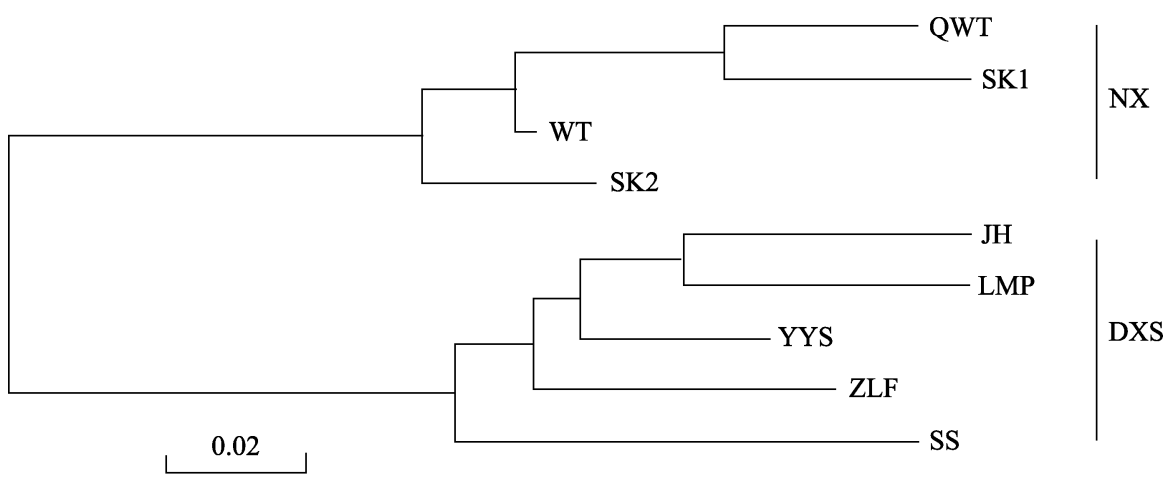

图3 基于Nei's无偏距离的NJ法 (Neighbor-joining, NJ)构建的丹 霞梧桐 9 个群体的聚类图。缩写含 义同表1。

Fig. 3 Neighbor-joining network illustrating the genetic relationships among the nine Firmiana danxiaensis populations, based on Nei's (1987) unbiased genetic distance. Meanings of abbreviations are shown in Table 1.

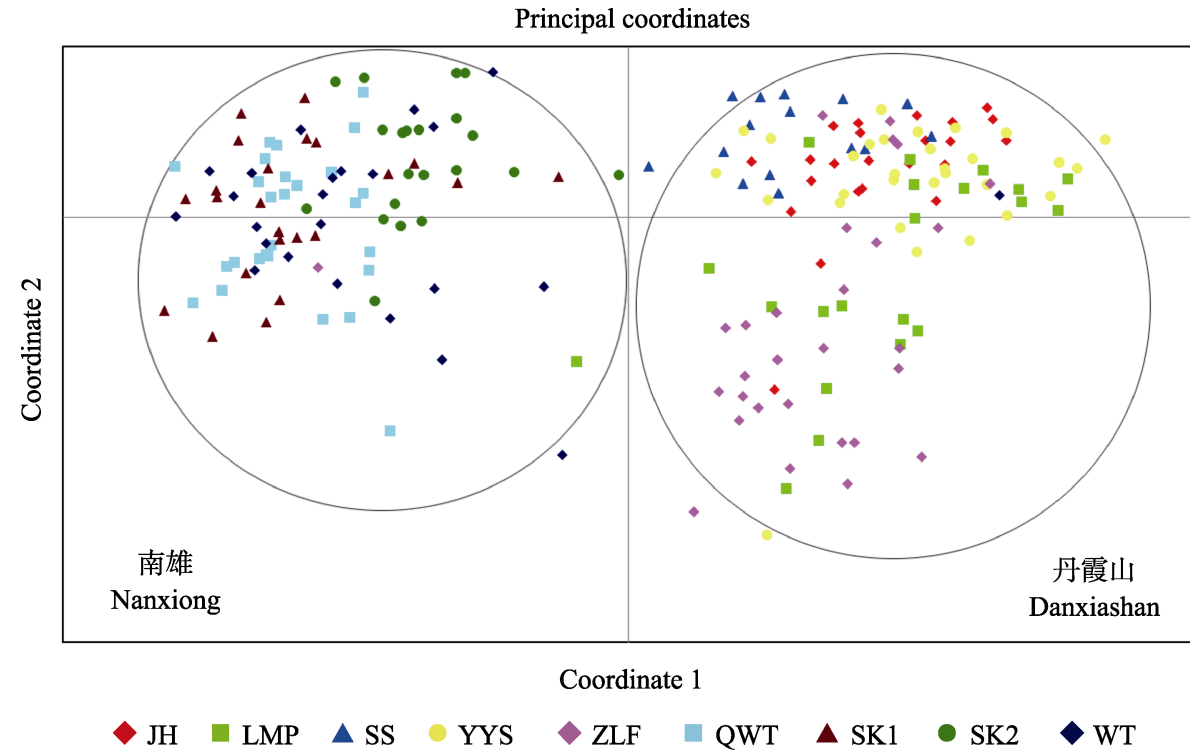

图4丹霞梧桐 9 个群体中两种 SSR表型的主成分分析(PCoA)。 缩写含义同表1。

Fig. 4 Principal coordinates analysis (PCoA) of two SSR phenotypes from all nine populations of Firmiana danxiaensis. Meanings of abbreviations are shown in Table 1.

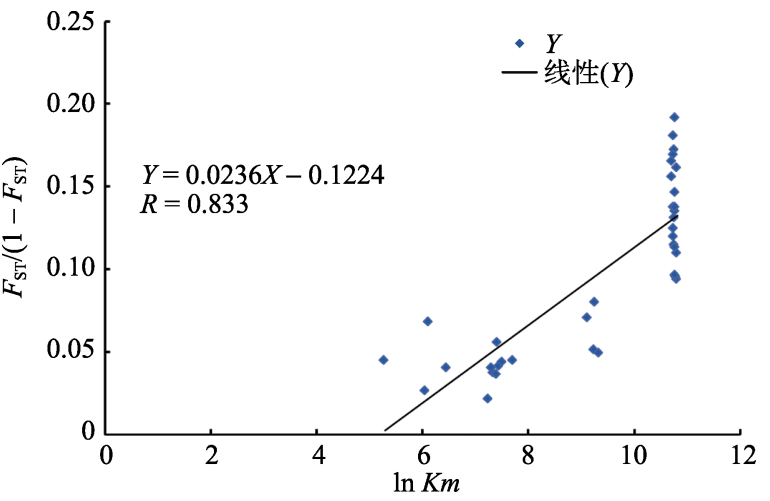

图5 丹霞梧桐 9 个群体的地理距离与遗传距离的相关性 检验

Fig. 5 Geographical distance against genetic distance for the nine Firmiana danxiaensis populations

\section{4 瓶颈效应检测}

利用Bottleneck提供的逐步突变模型和双相突 变模型检测 9 个群体的瓶颈效应。锦湖 $(\mathrm{JH})$ 、韶石山 $(\mathrm{SS}) 、$ 水库 1 (SK1)和水库2 (SK2)群体在双相突变模
型(TPM)中杂合子过剩 $(P<0.01)$, 而在逐步突变模 型(SMM)中未出现杂合子过剩现象(表6)。

\section{5 群体进化历史}

DIY ABC分析结果表明，设定的4个进化事件 的后验概率 $(P P)$ 分别为 $0.4303,0.2740,0.1724$ 和 0.1233 , 最高值出现在进化事件1中，说明进化事件 1 的假设可信度最高(图6)。根据进化事件1的描述， 丹霞山和南雄群体在 $t 1$ 时由一个共同的祖先群体分 化而来, 群体进化过程中没有经历瓶颈事件。2个群 体的历史分化时间 $t 1$ 估测值为 2,870 代(generation), 分化后有效群体大小分别为 7,290 和 5,550 个样本(表 7, 附录2)。

\section{3 讨论}

\section{1 遗传变异模式}

微卫星分析结果表明, 丹霞梧桐总的遗传多样 性中等 $(H t=0.631)$, 低于长果安息香(Changio- 
styrax dolichocarpa, Yao et al, 2007)、青钱柳(Cyclocary apaliurus, Kou et al, 2016)和八角莲(Dysosma versipellis, Qiu et al, 2009)等亚热带落叶阔叶树种, 但群体内遗传多样性相对较高 $(H s=0.546)$ 。群体间,
特别是不同地理群体间存在显著的遗传分化 $\left(F_{\mathrm{ST}}=\right.$ $0.150, P<0.01)$ 。丹霞梧桐现存种群的遗传变异模 式类似于其他亚热带阔叶树种(叶俊伟等, 2017), 但 与长命、风媒传粉植物的遗传变异模式有明显不同

表6 丹霞梧桐群体瓶颈效应检测

Table 6 Bottleneck detection for Firmiana danxiaensis

\begin{tabular}{|c|c|c|c|}
\hline \multirow{2}{*}{$\begin{array}{l}\text { 群体 } \\
\text { Population }\end{array}$} & \multirow{2}{*}{$\begin{array}{l}\text { 编号 } \\
\text { Codes }\end{array}$} & \multicolumn{2}{|l|}{ Wilcoxon检验 Wilcoxon test } \\
\hline & & $\begin{array}{l}\text { 双相突变模型 } \\
\text { Two-phased mutation model (TPM) }\end{array}$ & $\begin{array}{l}\text { 逐步突变模型 } \\
\text { Stepwise mutation model (SMM) }\end{array}$ \\
\hline 锦湖 Jinhu & $\mathrm{JH}$ & 0.00200 & 0.22115 \\
\hline 老苗圃 Laomiaopu & LMP & 0.16236 & 0.95929 \\
\hline 韶石山 Shaoshishan & SS & 0.00005 & 0.20856 \\
\hline 阳元山 Yangyuanshan & YYS & 0.12310 & 0.95063 \\
\hline 长老峰 Zhanglaofeng & ZLF & 0.13226 & 0.98288 \\
\hline 鹗㚔湖 Yuanyanghu & QWT & 0.16236 & 0.94518 \\
\hline 水库1 Shuiku1 & SK1 & 0.00237 & 0.22115 \\
\hline 水库2 Shuiku2 & SK2 & 0.00694 & 0.63314 \\
\hline 柴岭 Chailing & WT & 0.05935 & 0.64906 \\
\hline
\end{tabular}
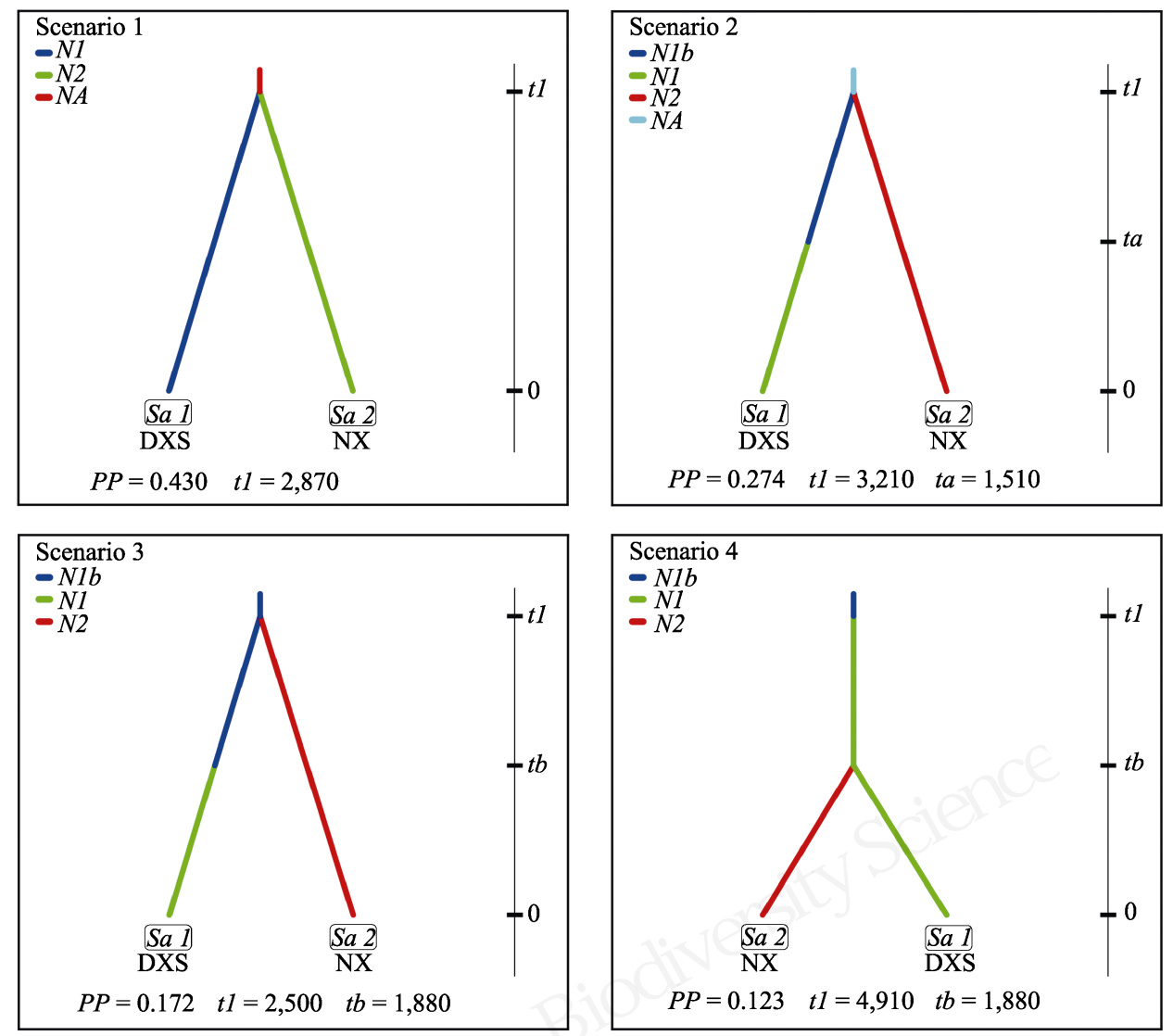

图6 基于近似贝叶斯算法的丹霞梧桐 4 个进化事件模型 $(K=2)$ 。缩写含义同表1。DXS代表丹霞山组群, NX代表南雄组群。 $P P$ 代表后验概率, N1, N2, N1b, NA分别代表有效群体大小, $t 1, t a, t b$ 分别代表进化代数。

Fig. 6 Four scenarios for Firmiana danxiaensis based on Approximate Bayesian Computation $(K=2)$. Meanings of abbreviations are shown in Table 1. DXS represents Danxiashan group. NX represents Nanxiong group. $P P$ represents posterior probability. $N 1, N 2$, $N 1 b, N A$ represent effective population size, respectively. $t 1, t a, t b$ represent generation. 
表7 基于近似贝叶斯算法的各进化事件的后验分布的中值估计

Table 7 Median estimation of posterior distributions for each scenario based on Approximate Bayesian Computation (ABC)

\begin{tabular}{lllll}
\hline & 进化事件1 & 进化事件2 & 进化事件3 & $\begin{array}{l}\text { 进化事件 4 } \\
\text { Scenario 4 }\end{array}$ \\
\hline Scenario 1 & Scenario 2 & 0.1724 & 0.1233 \\
\hline 后验概率 Posterior probability $(P P)$ & 0.4303 & 0.2740 & 2,500 & 4,910 \\
代数 Generation $(t 1)$ & 2,870 & 3,210 & 1,880 & - \\
代数 Generation $(t a)$ & - & 1,510 & - & 1,880 \\
代数 Generation $(t b)$ & - & - & 6,070 & 646 \\
群体大小 Effective population size $(N 1 b)$ & - & 4,830 & 8,260 & 7,220 \\
群体大小 Effective population size $(N 1)$ & 7,290 & 7,800 & 5,430 & 5,630 \\
群体大小 Effective population size $(N 2)$ & 5,550 & 5,700 & - & - \\
群体大小 Effective population size $(N 3)$ & - & - & - & - \\
群体大小 Effective population size $(N A)$ & 4,450 & 4,130 & & \\
\hline
\end{tabular}

(较高的种内遗传多样性和较低的种间遗传分化) (Hamrick et al, 1992; Hamrick \& Godt, 1996; Nybom, 2004)。植物遗传多样性和遗传分化受多种因素的影 响, 如繁殖系统、基因流、遗传漂变、气候变化、地 理隔离和人为干扰等(Freeland et al, 2011; 文亚峰 等, 2010)。特定物种的遗传变异模式是以上多因素 综合作用的结果。长期的地理隔离和现代人为干 扰可能是形成丹霞梧桐当前遗传变异模式的主要 原因。

地理隔离会减少植物群体间的联系和遗传物 质交换, 增加遗传漂变的几率, 导致群体内遗传多 样性降低, 群体间遗传分化加大(Templeton et al, 2001; Frankham et al, 2002), 甚至产生新的隔离种。 分析结果显示现存丹霞梧桐群体间存在极显著的 地理隔离 $(R=0.833, P=0.01)$ 。梧桐科植物是第三 纪子遗植物, 在长期的历史进化过程中, 古地质、 气候的剧烈变化使其群体数量持续减少, 有限的个 体能够适应小环境(避难所)存活繁衍至今。作为丹 霞地貌的特有种, 丹霞梧桐对地质和土壤的特殊要 求进一步限制了其分布范围, 加大了地理隔离。与 Chen等(2014)对丹霞梧桐的研究相比较, 本研究显 示出更高的种内遗传多样性和群体间遗传分化, 这 是因为我们的采样范围扩大到了南雄地区, 地理距 离的增大, 种群之间的长期隔离最终形成了当前的 遗传变异模式。

全新世以来, 人类活动对全球生物多样性产生 了深刻影响, 成为现代物种灭绝的主要原因 (Palumbi, 2001; Tilman \& Lehman, 2001)。森林砍 伐、资源过度利用、农业、旅游活动、环境污染等
人类活动的增加使丹霞梧桐的生境遭到了严重破 坏, 种群数量迅速减少, 群体片断化日趋严重。群 体近交系数为负值 $\left(F_{\mathrm{IS}}=-0.229\right)$, 说明自然状态下 丹霞梧桐以异交为主, 这与其风媒传粉、鸟类传播 种子的生殖特性一致。但这些有利于基因流动的繁 殖特性仍然难以抵消由于地理隔离和人为干扰所 带来的群体规模缩小及片断化效应, 进而引起遗传 多样性的丢失和遗传分化的加剧。

\section{2 群体遗传结构}

AMOVA巢式分析结果表明, 丹霞梧桐的遗传 变异主要存在于群体内, 但群体间特别是地理组群 间仍存在较大程度的遗传变异。STRUCTURE分析 得到的最优 $K$ 值为 2 , 可将 9 个群体划分为两组, 正 好与两个地理组群的采样点相符合。随着 $K$ 值的增 大 $(K=3,4)$, 丹霞山组群中出现了新的基因库, 说 明丹霞山群体的杂合性更高, 遗传背景更为复杂。

$\mathrm{NJ}$ 系统发育分析和个体 PCoA 分析结果与 STRUCTURE分析结果一致, 进一步说明丹霞梧桐 两个地理群体各自经历了独立的进化路线, 其遗传 结构与系统发育地理格局之间有密切关系。

丹霞梧桐清晰的群体遗传结构一定程度上反 映出了冰期避难所信息。最近的 100 万年, 冰期的循 环时间约为 10 万年(Howard, 1997)。这意味着每隔 10 万年, 就会有气温和降雨量发生动荡变化的冰期和 间冰期出现, 在此过程中, 只有适应气候和环境剧 烈变化的物种或群体才得以成活。气候和环境的反 复变化加快了植物的适应性进化, 也使不同避难所 群体间的遗传分化持续加大。本研究表明, 丹霞梧 桐的群体遗传结构符合多个避难所模式, 与中国亚 
热带地区阔叶林植物谱系地理学研究结果相吻合 (叶俊伟等, 2017)。我们推测第四纪冰期时, 南岭周 边可能存在多个丹霞梧桐避难所。现存丹霞山群体 在丹霞山分布面积广, 具有较高的遗传多样性和私 有等位基因, 遗传背景复杂, 故丹霞山可能属于冰 期大型避难所。南雄群体遗传多样性相对较低, 遗 传结构单一，应是潜在的小型避难所。

\section{3 地理群体分化时间}

DIY ABC分析允许考虑复杂的群体进化历史, 包括可能的群体分化, 杂交(混合)或种群数量变化 的任何组合，通过对进化事件的置信度评估，实现 最优进化事件的检验。群体历史进化事件的发生或 分化时间常以物种的世代更替代数(generation)的形 式给出。研究分析表明, 丹霞梧桐两个地理群体(丹 霞山和南雄)由同一个祖先群体分化而来, 分化发 生在2,870代(t1)之前。不同物种有各自特定的世代 更替时间, 我们无法确定自然条件下丹霞梧桐每代 繁殖更替的准确时间，但丹霞梧桐属长命阔叶树种， 通常需要8-10年开花结实, 自然条件下受多种因素 影响性成熟会有所延迟。我们根据丹霞梧桐和亚热 带落叶阔叶树种的生物学特性, 设定其每代繁殖更 替时间为30-50年，最优进化事件1所对应的群体分 化时间为86,100-143,500年, 即丹霞山和南雄地理 群体的分化时间发生在约 10 万年之前。

根据古地质和气候变化史, 第四纪冰期东亚地 区可能经历了 4 次亚冰期和 5 次间冰期(景才瑞, 1963)。在亚冰期，植物受温度和降雨量的减少会退 缩至避难所, 间冰期随着温度和环境条件的好转, 植物种群会以避难所为中心逐渐扩大分布范围。

DIY ABC 分析结果显示丹霞山和南雄群体的分化 时间约在 10 万年之前, 丹霞梧桐似乎并未受到末次 盛冰期(LGM, 21,000年前)的影响。我们推测10万年 前, 丹霞梧桐广泛分布于南岭周边地区, 受第四纪 第三次亚冰期的影响, 南岭北部的丹霞梧桐因气候 剧烈变化而灭绝, 仅在南岭南部较适宜的环境得以 保存并繁衍至今, 丹霞山和南雄是丹霞梧桐最主要 的两个冰期避难所。分化后, 两地理群体的有效群 体大小分别为 7,290 (丹霞山)和5,550(南雄) 个样本, 丹霞山群体分布面积更为广泛, 原始群体数量保存 较多, 群体间基因交流频繁, 这也解释了丹霞山群 体为什么具有较高的遗传多样性和稀有等位基因。 南雄地区因特殊的小气候环境, 丹霞梧桐仅在沟谷
中有少量分布, 群体间显示出了较近的亲缘关系和 较小的遗传分化。根据我们的野外调查，丹霞梧桐 目前在韶关地区的分布数量约 7,000株, 新生代以 后，人类活动的增加和对自然资源的破坏是其有效 群体数量减少的主要原因。

\section{4 丹霞梧桐的保护策略}

丹霞梧桐起源古老，自然分布区域狭窄，其发 现至今不过 30 年时间, 相关研究工作基础薄弱。本 研究中, 虽然Bottleneck检测和DIY ABC分析均没 有显示明显的瓶颈事件，但如果不采取有效的保护 措施，随着丹霞梧桐群体数量的减少和生境片断化 的加剧，必然会对该物种的长期生存造成影响。

科学保护的第一步是掌握丹霞梧桐的自然分 布。根据丹霞梧桐现有分布地区的气候资料, 并结 合丹霞地貌特征，我们发现南岭南部的丹霞地貌区 是丹霞梧桐的潜在分布地，广西、广东、福建三省 区的玉林-韶关-武夷山沿线应作为资源调查的重 点(黄进等, 2015)。南岭北部丹霞地貌区的小气候环 境也可能会有该物种的分布，主要包括2010年被列 入“世界自然遗产”的典型丹霞地貌区，如湖南峎 山、贵州赤水、江西龙虎山、浙江江郎山、福建泰 宁等地(彭华, 2011)。

针对丹霞梧桐的现有种群, 就地保护是最有效 的保护措施。丹霞地貌小尺度范围内有着高度多样 的生态系统，生境多变，丹霞梧桐多生长于坡度较 大的山体岩壁上, 这种特殊地貌的生境中尽管环境 恶劣, 但由于丹霞梧桐根系发达, 茎基萌藥能力强, 大部分长势良好。保护好现有群落和生境, 才能最 大限度地保存该物种及其遗传多样性。相比较而言, 丹霞山自然保护区的长老峰(ZLF)、韶石山(SS)群体 遗传多样性高, 含有较多私有等位基因, 应予以优 先重点保护。对于锦湖(JH)、阳元山(YYS)等靠近 旅游区的群体，要做好宣传保护，定期监测，评估 旅游活动对丹霞梧桐群体的影响。南雄山地的丹霞 梧桐数量较少，但基因资源特殊，应尽快建立自然 保护区予以有效保护。同时，通过建立种质资源圃、 人工种苗扩繁、自然回归试验等措施，对于该物种的 异地保护、种群恢复和开发利用都具有重要意义。

致谢：广东省韶关市丹霞山管理委员会陈昉主任、 陈再雄园长和广东省南雄市林业局钟平生主任在 
资源调查和样本采集中给予支持和帮助, 特此感 谢！同时特别感谢编辑老师认真细致的修改!

\section{参考文献}

Chen L, Zhou H, Wang MQ, Wu XT, Lin XY, Zhang Y, Wen YF (2018) Community characteristics comparison of Firmiana danxiaensis species. Chinese Wild Plant Resources, 37(2), 46-49. (in Chinese with English abstract) [陈璐, 周 宏, 王敏求, 武星䄧, 林雪芗, 张原, 文亚峰 (2018) 丹 霞梧桐群落特征比较研究. 中国野生植物资源, 37(2), 46-49.]

Chen SF, Li MW, Hou RF, Liao WB, Zhou RC, Fan Q (2014) Low genetic diversity and weak population differentiation in Firmiana danxiaensis, a tree species endemic to Danxia landform in northern Guangdong, China. Biochemical Systematics \& Ecology, 55, 66-72.

Cornuet JM, Luikart G (1996) Description and power analysis of two tests for detecting recent population bottlenecks from allele frequency data. Genetics, 144, 2001-2014.

Cornuet JM, Pudlo P, Veyssier J, Dehne-Garcia A, Gautier M, Leblois R, Marin JM, Estoup A (2014) DIYABC v2.0: A software to make approximate Bayesian computation inferences about population history using single nucleotide polymorphism, DNA sequence and microsatellite data. Bioinformatics, 30, 1187-1189.

Demesure B, Sodzi N, Petit RJ (1995) A set of universal primers for amplification of polymorphic non-coding regions of mitochondrial and chloroplast DNA in plants. Molecular Ecology, 4, 129-131.

Earl DA, vonHoldt BM (2012) STRUCTURE HARVESTER: A website and program for visualizing STRUCTURE output and implementing the Evanno method. Conservation Genetics Resources, 4, 359-361.

Excoffier L, Lischer HEL (2010) Arlequin suite ver 3.5: A new series of programs to perform population genetics analyses under Linux and Windows. Molecular Ecology Resources, 10, 564-567.

Frankham R, Ballou JD, Briscoe DA (2002) Introduction to Conservation Genetics. Cambridge University Press, Cambridge, UK.

Freeland JR, Petersen SD, Kirk H (2011) Molecular Ecology, 2nd Edn. Wiley-Blackwell, West Sussex.

Goudet J (1995) FSTAT(Version 1.2): A computer program to calculate F-Statistics. Journal of Heredity, 86, 485-486.

Hamrick JL, Godt MJW (1996) Effects of life history traits on genetic diversity in plant species. Philosophical Transactions of the Royal Society B: Biological Sciences, 351, 1291-1298.

Hamrick JL, Godt MJW, Sherman-Broyles SL (1992) Factors influencing levels of genetic diversity in woody plant species. New Forests, 6, 95-124.

Harrison SP, Yu G, Takahara H, Prentice IC (2001) Palaeovegetation (communications arising): Diversity of temperate plants in East Asia. Nature, 413, 129-130.
Hewitt GM (2004) Genetic consequences of climatic oscillations in the Quaternary. Philosophical Transactions of the Royal Society of London, 359, 183-195.

Hewitt GM (1996) Some genetic consequences of ice ages, and their role in divergence and speciation. Biological Journal of the Linnean Society, 58, 247-276.

Howard WR (1997) A warm future in the past. Nature, 388, 418-419.

Huang J, Chen ZJ, Qi DL (2015) Study on distribution of Danxia Landform in China (first). Mountain Research, 33, 385-396. (in Chinese with English abstract) [黄进, 陈致均, 齐德利 (2015) 中国丹霞地貌分布(上). 山地学报，33, 385-396.]

Jakobsson M, Rosenberg NA (2007) CLUMPP: A cluster matching and permutation program for dealing with label switching and multimodality in analysis of population structure. Bioinformatics, 23, 1801-1806.

Jarne P, Lagoda PJL (1996) Microsatellites, from molecules to populations and back. Trends in Ecology \& Evolution, 11(10), 424-429.

Jing CR (1963) On the Quaternary glacial period in China. Scientific Research Papers, (1963), 253-268. (in Chinese) [景才瑞 (1963) 试论中国第四纪冰期. 科学研究论文集, (1963), 253-268.]

Kalinowski ST (2005) HP-RARE 1.0: A computer program for performing rarefaction on measures of allelic richness. Molecular Ecology Resources, 5, 187-189.

Kou YX, Cheng SM, Tian S, Li B, Fan DM, Chen YJ, Soltis DE, Soltis PS, Zhang ZY (2016) The antiquity of Cyclocary apaliurus (Juglandaceae) provides new insights into the evolution of relict plants in subtropical China since the late early Miocene. Journal of Biogeography, 43, 351-360.

Luo XY, Chen QH, Cai CR, Zeng HN, Ren B, Zheng WL, Feng JY (2015) Analysis on geographical elements of the community of plant species with extremely small population Firmiana danxiaensis. Journal of Shaoguan University, 36(12), 28-31. (in Chinese with English abstract) [罗晓莹, 陈秋慧，蔡纯榕，曾浩宁，任斌，郑万里，冯均尧 (2015) 极小种群植物丹霞梧桐群落的地理区系成分分析. 韶关 学院学报, 36(12), 28-31.]

Myers N, Mittermeier RA, Mittermeier CG, Da FG, Kent J (2000) Biodiversity hotspots for conservation priorities. Nature, 403, 853-858.

Nybom H (2004) Comparison of different nuclear DNA markers for estimating intraspecific genetic diversity in plants. Molecular Ecology, 13, 1143-1155.

Ouyang J, Huang J (2011) Spatial distribution of Danxia landforms in China. Geospatial Information, 9(6), 55-59. (in Chinese with English abstract) [欧阳杰, 黄进 (2011) 中国 丹霞地貌空间分布探讨. 地理空间信息, 9(6), 55-59.]

Palumbi SR (2001) Humans as the World's Greatest Evolutionary Force. Science, 293, 1786-1790.

Peakall R, Smouse PE (2006) GENALEX 6: Genetic analysis in Excel, population genetic software for teaching and research. Molecular Ecology Resources, 6, 288-295. 
Peng H (2011) Danxia of China towards the world. Map, (6), 114-121. (in Chinese) [彭华 (2011) 走向世界的中国丹 霞. 地图, (6), 114-121.]

Peng SL (2011) Comprehensive Scientific Investigation for Animal and Plant Resources in Mount Danxia, Guangdong. Science Press, Beijing. (in Chinese) [彭少麟 (2011) 广东 丹霞山动植物资源综合科学考察. 科学出版社, 北京.]

Pritchard JK, Stephens MJ, Donnelly PJ (2000) STRUCTURE, version 2.3.3, inference of population structure using multilocus genotype data. Genetics, 155, 945-959.

Qiu YX, Fu CX, Comes HP (2011) Plant molecular phylogeography in China and adjacent regions: Tracing the genetic imprints of Quaternary climate and environmental change in the world's most diverse temperate flora. Molecular Phylogenetics and Evolution, 59, 225-244.

Qiu YX, Guan BC, Fu CX, Comes HP (2009) Did glacials and /or interglacials promote allopatric incipient speciation in East Asian temperate plants? Phylogeographic and coalescent analyses on refugial isolation and divergence in $D y$ sosma versipellis. Molecular Phylogenetics and Evolution, 51, 281-293.

Rosenberg NA (2010) DISTRUCT: A program for the graphical display of population structure. Molecular Ecology Notes, 4, 137-138.

Selkoe KA, Toonen RJ (2006) Microsatellite for ecologists: A practical guide to using and evaluating microsatellite markers. Ecology Letters, 9, 615-629.

Takezaki N, Nei M, Tamura K (2010) POPTREE2: Software for constructing population trees from allele frequency data and computing other population statistics with Windowsinterface. Molecular Biology \& Evolution, 27, 747-752.

Tao JR (1992) Study on the fossil flowers of angiosperm. Acta Botanica Sinica, 34, 240-242. (in Chinese) [陶君容 (1992) 被子植物的花化石研究. 植物学报, 34, 240-242.]

Templeton AR, Robertson RJ, Brisson J, Strasburg J (2001) Disrupting evolutionary processes: The effect of the habitat fragmentation on collared lizards in the Missouri Ozarks. Proceedings of the National Academy of Sciences, USA, 98, 5426-5432.

Tilman D, Lehman C (2001) Human-caused environmental change: Impacts on plant diversity and evolution. Proceedings of the National Academy of Sciences, USA, 98, 5433-5440.

Tsumura Y, Yoshimura K, Tomaru N, Ohba K (1995) Molecular phylogeny of conifers using RFLP analysis of PCR-amp- lified specific chloroplast genes. Theoretical and Applied Genetics, 91, 1222-1236.

Wang S, Xie Y (2004) China Species Red List (Vol. 1). Higher Education Press, Beijing. (in Chinese) [汪松, 解炎 (2004) 中国物种红色名录(第一卷). 高等教育出版社, 北京.]

Wen YF, Han WJ, Wu S (2010) Plant genetic diversity and its influencing factors. Journal of Central South University of Forestry \& Technology, 30(12), 80-87. (in Chinese with English abstract) [文亚峰, 韩文军, 吴顺 (2010) 植物遗 传多样性及其影响因素. 中南林业科技大学学报, 30(12), 80-87.]

Xie XM, Zhang SZ, Li Y, Wu H (2003) Review of taxonomic studies on Sterculiaceae. Guihaia, 23, 311-317. (in Chinese with English abstract) [解新明, 张寿洲, 李勇, 吴鸿 (2003) 梧桐科分类学研究评述. 广西植物, 23, 311-317.]

Xu SJ (2002) The distribution of the Sterculiaceous plants in China. Guihaia, 22, 494-498. (in Chinese with English abstract) [徐颂军 (2002) 梧桐科植物在中国的地理分布. 广西植物, 22, 494-498.]

Xu SJ, Xu XH (2001) Geographical distribution of Sterculiaceae. Journal of Tropical and Subtropical Botany, 9(1), 19-30. (in Chinese with English abstract) [徐颂军, 徐祥浩 (2001) 梧桐科植物的地理分布. 热带亚热带植物学报, 9, 19-30.]

Xu XH, Qiu HX, Xu SJ (1987) New species and variety of Sterculiaceae from China. Journal of South China Agricultural University, 8(3), 1-5. (in Chinese with English abstract) [徐祥浩, 丘华兴, 徐颂军 (1987) 中国梧桐科植物 的新种和新变种. 华南农业大学学报, 8(3), 1-5.]

Yao XH, Ye QG, Kang M, Huang HW (2007) Microsatellite analysis reveals interpopulation differentiation and gene flow in the endangered tree Changiostyrax dolichocarpa (Styracaceae) with fragmented distribution in central China. New Phytologist, 176, 472-480.

Ye JW, Zhang Y, Wang XJ (2017) Phylogeographic history of broad-leaved forest plants in subtropical China. Acta Ecologica Sinica, 37, 5894-5904. (in Chinese with English abstract) [叶俊伟, 张阳, 王晓娟 (2017) 中国亚热带地区 阔叶林植物的谱系地理历史. 生态学报, 37, 5894-5904.]

Ying JS (2001) Species diversity and distribution pattern of seed plants in China. Biodiversity Science, 9, 393-398. (in Chinese with English abstract) [应俊生 (2001) 中国种子 植物物种多样性及其分布格局. 生物多样性, 9, 393-398.]

(责任编委: 邱英雄 责任编辑: 间文杰)

\section{附录 Supplementary Material}

附录 1 基于近似贝叶斯算法的先验概率的参数设置

Appendix 1 Parameters for the prior distribution in Approximate Bayesian Computation http://www.biodiversity-science.net/fileup/PDF/2018223-1.pdf

附录 2 最优进化事件的前验概率和后验概率的参数分布

Appendix 2 Prior and posterior distributions for each parameters for the priority scenario http://www.biodiversity-science.net/fileup/PDF/2018223-2.pdf 
武星䄧, 陈璐, 王敏求, 张原, 林雪莹, 李金金玉, 周宏, 文亚峰. 丹霞梧桐群体遗传结构及其遗传分化. 生物 多样性, 2018, 26 (11): 1168-1179.

http://www.biodiversity-science.net/CN/10.17520/biods.2018223

附录 1 基于近似贝叶斯算法的先验概率的参数设置

Appendix 1 Parameters for the prior distribution in Approximate Bayesian Computation

\begin{tabular}{|c|c|c|}
\hline 参数 Parameters & 最小值 Min. & 最大值 Max. \\
\hline \multicolumn{3}{|l|}{ 有效群体大小 Effective population } \\
\hline \multicolumn{3}{|l|}{ size } \\
\hline N1 & 10 & 10,000 \\
\hline N2 & 10 & 10,000 \\
\hline$N A$ & 10 & 10,000 \\
\hline$N 1 b$ & 10 & 10,000 \\
\hline \multicolumn{3}{|l|}{ 代数 Generation } \\
\hline$t 1$ & 1 & 10,000 \\
\hline ta & 1 & 10,000 \\
\hline$t b$ & 1 & 10,000 \\
\hline \multicolumn{3}{|l|}{ 突变模型 Mutation models } \\
\hline \multicolumn{3}{|l|}{ 平均突变概率 } \\
\hline \multicolumn{3}{|l|}{ Mean mutation rate } \\
\hline 单个位点突变概率 & & \\
\hline \multicolumn{3}{|l|}{ Individual locus mutation rate } \\
\hline \multicolumn{3}{|l|}{ 先验概率平均系数 } \\
\hline \multicolumn{3}{|l|}{ Mean coefficient $P$} \\
\hline 平均单个核苷酸插入的概率 & & \\
\hline \multicolumn{3}{|l|}{ Mean single nucleotide insertion rate } \\
\hline \multicolumn{3}{|l|}{ 单个位点核苷酸插入的概率 } \\
\hline $\begin{array}{l}\text { Individual locus single nucleotide } \\
\text { insertion rate }\end{array}$ & $1.00 \mathrm{E}-09$ & $1.00 \mathrm{E}-03$ \\
\hline
\end{tabular}


武星粀，陈璐，王敏求，张原，林雪芗，李金金玉，周宏，文亚峰. 丹霞梧桐群体遗传结构及其遗传分化. 生物 多样性, 2018, 26 (11): 1168-1179.

http://www.biodiversity-science.net/CN/10.17520/biods.2018223


附录 2 最优进化事件的前验概率和后验概率的参数分布

Appendix 2 Prior and posterior distributions for each parameters for the priority scenario 